\title{
Chemoprophylaxis of Influenza A (H1N1) in the perspective of the Brazilian Unified Health System (SUS): a budget impact analysis
}

\section{Luisa Vecoso*, Marcus Silva, Everton Silva, Tais Galvao}

\begin{abstract}
BACKGROUND: In Brazil, the prophylaxis of influenza with the antivirals oseltamivir and zanamivir is cost-effective and recommended for the groups with higher risk of complications. In this study we estimated the impact of the chemoprophylaxis in the health system budget from 2017 to 2023. METHODS: We calculated the size of the risk population, expenditure with prophylaxis and the budget impact in 2017 to 2018 with official demographic and vaccine coverage data, and aqcuisition of antivirals by SUS. The estimative from 2019 to 2023 was conducted using trigonometric models. RESULTS AND CONCLUSION: The risk population variated from 2.3 to 5.5 millions of individuals and the budget impact variated from $0.74 \%$ (2018) and 6.9\% (2019).
\end{abstract}

\section{Key words:}

Budget impact, influenza, Brazil.

\section{Introduction}

Oseltamivir and zanamivir are antivirals recommended in Brazil by the Ministry of Health for the prophylaxis of influenza in high risk groups (1), which was evaluated as cost-effective in the Brazilian scenario in our previous study. In the current study, the impact of the technology in the Unified Health System (SUS) budget was evaluated in the time-horizon of 5 years, by the estimative of the risk population and drug acquisition in the period. In budget impact analyses, the real expected cost is given by clinical and economic data, translated as important tools for the management of the health system. Our study was conducted according to national guidelines (2).

\section{Results and Discussion}

The estimated Brazilian population until 2023 was obtained from official demographic data. The annual incidence of Influenza $A(\mathrm{H} 1 \mathrm{~N} 1)$ in the risk population was estimated from cases of severe acute respiratory syndrome (SARS) reported since 2009, obtained from official epidemiological data. We used the estimated annual SARS incidence and population to calculate and project the SARS frequency until 2023. The frequency of the risk population in the total population was calculated from the non-vaccinated individuals in the risk population (obtained from official vaccine coverage data) in 2017 and 2018, and estimated until 2023 with the trigonometric model $\mathbf{y}=\mathbf{0 , 0 0 7} \cdot \cos (\mathbf{m x}) \mathbf{+ 0 , 0 1 8}$, therefore we obtained the size of the risk population (Table 1).

Table 1. Estimative of the target population for post-exposure prophylaxis from 2018 to 2023

\begin{tabular}{|l|l|l|l|l|l|}
\hline Year & $\begin{array}{l}\text { Brazilian } \\
\text { population }\end{array}$ & $\begin{array}{l}\text { SARS } \\
\text { (frequency) }\end{array}$ & $\begin{array}{l}\text { SARS } \\
\text { (n) }\end{array}$ & $\begin{array}{l}\text { Risk } \\
\text { population } \\
\text { (frequency) }\end{array}$ & $\begin{array}{l}\text { Risk } \\
\text { population } \\
\text { (n) }\end{array}$ \\
\hline 2018 & $209,186,802$ & 0.0000606 & 12,687 & 0.011077 & $2,317,215$ \\
\hline 2019 & $210,659,013$ & 0,0002538 & 53,471 & 0.025644 & $5,402,131$ \\
\hline 2020 & $212,077,375$ & 0.0002538 & 53,831 & 0.011077 & $2,349,235$ \\
\hline 2021 & $213,440,458$ & 0.0000606 & 12,945 & 0.025644 & $5,473,459$ \\
\hline 2022 & $214,747,509$ & 0.0001466 & 31,487 & 0.011077 & $2,378,812$ \\
\hline 2023 & $215,998,724$ & 0.0003015 & 65,132 & 0.025644 & $5,539,063$ \\
\hline
\end{tabular}

The frequency of prophylaxis among the risk population in 2017 and 2018 was calculated from the risk population and the treatment consumed in this period. The projection of this frequency from 2019 to 2023 was projected by the trigonometric model $\mathbf{y}=\mathbf{0 , 0 5 4} \cdot \cos (2 \pi x / 1,5)+0,068$. Finally, the budget impact was calculated (Table 2). We did not use an alternative scenario, as the technology is already included in SUS. The sensitivity analyses showed that an expense freeze would end in greater impact. Variations in the adherence to prophylaxis in 1\% and $5 \%$ would also affect the budget impact (Figure 1).

Table 2. Budget impact of the post-exposure prophylaxis from 2018 to 2023

\begin{tabular}{|l|l|l|l|l|l|}
\hline Year & $\begin{array}{l}\text { Risk } \\
\text { population }\end{array}$ & $\begin{array}{l}\text { Prophylaxis } \\
\text { (frequency) }\end{array}$ & $\begin{array}{l}\text { Expenditure } \\
\text { with prophylaxis } \\
(\mathrm{R} \$)\end{array}$ & $\begin{array}{l}\text { Budget } \\
\text { impact }\end{array}$ \\
\hline 2018 & $2,317,215$ & 0.0293 & $2,675,523.18$ & $363,093,489.56$ & $0.74 \%$ \\
\hline 2019 & $5,402,131$ & 0.1270 & $27,043,431.18$ & $392,193,385.62$ & $6.90 \%$ \\
\hline 2020 & $2,349,235$ & 0.0429 & $3,970,678.91$ & $421,293,281.69$ & $0.94 \%$ \\
\hline 2021 & $5,473,459$ & 0.0429 & $9,251,245.86$ & $450,393,177.76$ & $2.05 \%$ \\
\hline 2022 & $2,378,812$ & 0.1270 & $11,908,493.75$ & $479,493,073.82$ & $2.48 \%$ \\
\hline 2023 & $5,539,063$ & 0.0429 & $9,362,129.93$ & $508,592,969.89$ & $1.84 \%$ \\
\hline
\end{tabular}

Figure 1. Variations in the budget impact in each scenario of the sensitivity analysis

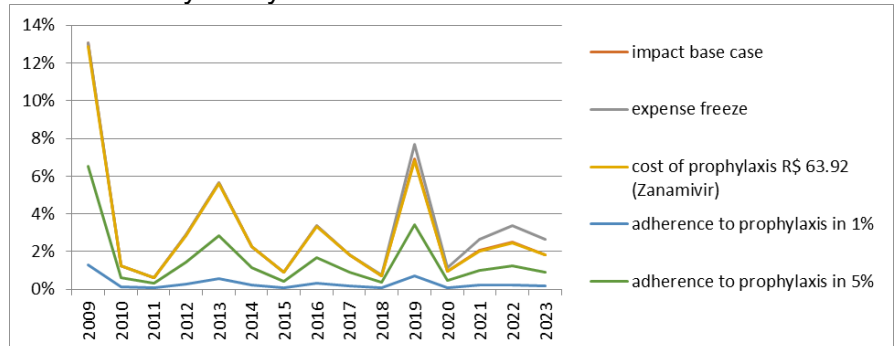

\section{Conclusions}

The impact of influenza prophylaxis ranged from less than $1 \%$ to $7 \%$.

Acknowledgement

The study was sponsored by HAOC - PROADI SUS.

\footnotetext{
1 Brasil. Ministério da Saúde. Secretaria de Vigilância em Saúde. Departamento de Vigilância das Doenças Transmissíveis. Protocolo de tratamento de Influenza 2017. Brasília: Ministério da Saúde; 2017. Available from:bvsms.saude.gov.br/bvs/publicacoes/protocolo_tratamento_influenza_20 17.pdf.

2 Brasil. Ministério da Saúde. Secretaria de Ciência, Tecnologia e Insumos Estratégicos. Departamento de Ciência e Tecnologia. Diretrizes metodológicas: análise de impacto orçamentário - manual para o Sistema de Saúde do Brasil 2012
} 